\title{
Narrative Time in Short Stories Colette El Khoury: A Genettian Reading
}

Robabe Ramezani Asst Prof of Arabic Language and Literature, Allameh Tabatabaei, Tehran, Iran.

Mina Nikjoo (Coresponding Author) mina.nikjo97@gmail.com Ma of Arabic Language and Literature, Allameh Tabatabaei, Tehran, Iran.

\begin{abstract}
Narratology concerns a set of principle about narrative styles, the systems that govern narrative or storytelling, and plot structure. Narration is a kind of two-layered timesequence: the time of narration and the narrative time. One of the important issues addressed by structuralist theory is the relationship between time and narrative, or crystallization of time within the narrative. Gérard Genette, Vladimir Propp, Grimas, and Tsveton Todorov are pioneers of this structuralist approach, who developed the study of narration in literature. Genet proposed five important narrative elements for analyzing the structures of literary texts: order, anachrony, continuity, frequency and narrative time. Colette El Khoury is prolific writer who has written significant short stories including "The Female Word", "The Years of Love and War", and "The Fragrant Dates, My Fingers Will Touch the Sun". Addressing issues like history and issue of women Colette El Khoury does not follow the natural and linear flow of events. He uses anachronic techniques such as flash back and flash forward to create suspense in her stories. Also, frequency and continuity play an important role in her stories. Such innovative narrative techniques can be used in roder to analyze classic literary text from a new angle.
\end{abstract}

Key words: Arabic Narratology, Narrative, Gerarad Genet's, Colette El Khoury, Short story

Citation: Ramezani, Robabeh; Nikjoo, Mina. Spring and Summer (2021). The narrative time in short stories of Colette Khoury based on Gerarard Genet's theory. Studies in Arabic Narratology, 2(4), 87-110. (In Arabic).

Studies in Arabic Narratology, Spring and Summer (2021), Vol. 2, No.4, pp. 87-110

Received: July25, 2021 Accepted: October17, 2021

(C)Faculty of Literature \& Humanities, University of Kharazmi and Iranian Association of Arabic Language \& Literature. 


\section{الزمن الروائي في القصص القصيرة لكوليت الخوري على ضوء}

\section{نظرية جيرار جينيت}

ramezani@atu.ac.ir

البريد الإلكتروني: - (n)

ربابة رمضاني

أستاذة مساعدة في قسم اللغة العربية وآدابها، بجامعة العلامة الطباطبائي، طهران، ايران. mina.nikjo97@gmail.com

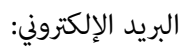
مينا نيكجو ماجستير قسم اللغة العربية وآدابها، بجامعة العلامة الطباطبائي، طهران، ايران. (الكاتبةالمسؤولة)

الإحالة: رمضاني، ربابه؛ نيكجو، مينا؛ ربيع وصيف (اr.r). الزمن الروائي في القصص القصيرة لكوليت الخوري على ضوء نظرية جيرار جينيت، دراسات في السردانية العربية، ؟(ع)، AV-•-11.

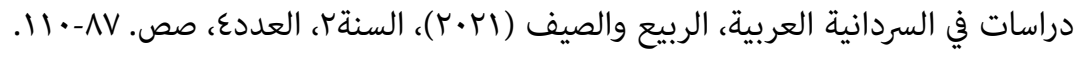

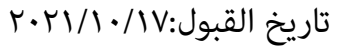

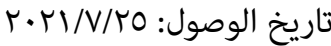
(ج) كلية الآداب والعلوم الإنسانية بجامعة الخوارزمي والجمعية العلمية الإيرانية للغة العربية

الملخص

السردية هي مجموعة من القواعد العامة حول أساليب السرد والأنظمة التي تحكم السرد أو السرد القصصي وهيكل الحبكة. السرد هو نوع من التسلسل الزمني ذي الوجهين؛ نقل الأحداث وزمن الرواية. إحدى القضايا المهمة التي تتناولها النظرية البنيوية هي العلاقة بين الزمن والسرد وكيفية تبلور الزمن في السرد. يعتبر جيرار جينيت، مع المنظرين مثل فلاديمير بروب، إي. جي. غريماس وتزيفيتون تودوروف، روّاد هذا المنهج البنيوي الذين درسوا الأساليب السردية للنص الأدبي. وقام جينيت 
بتحليل زمن السرد للنص بناءً على النظام واللازمنية والمدى والسعة والاستمرار و زمن السرد. وأما كوليت الخوري فهي كاتبة القصص القصيرة منها الكلمة الأنثى وسنوات الحب والحرب وعبق المواعيد وستلمس أصابعي الشمس، فهي كاتبة غزيرة الإنتاج وسجلت العديد من الأعمال تحت اسمها. بسبب قضايا مثل التاريخ وقضية المرأة، مل تتمكن كوليت الخوري من متابعة المسار الطبيعي والخط الروائي للأحداث. إنها تستخدم تقنيات السرد مثل الاسترجاع والاستباق لإيجاد الفراغ والتشويق في القصة وتقدمها خلال أربع طرق للازمنية كما تستخدم المدى والسعة والتواتر السردي في قصصها. الإنجاز الأكثر أهمية لهذه الأبحاث هو الاستفادة من المناهج الجديدة للنقد

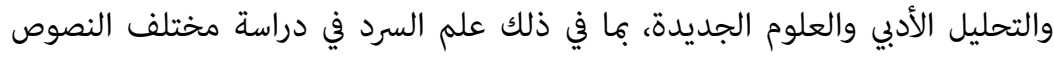
الكلاسيكية والحديثة مثل القصص القصيرة لكوليت الخوري.

الكلمات المفتاحية: السردية، جيرار جينيت، الزمن الروائي؛ كوليت الخوري، القصص القصيرة، السردانية العربية.

\section{المقدّمة}

لا السرديات أو علم السرد هي نظرية جذبت انتباه العديد من المنظرين والنقاد من جميع أنحاء العام في السنوات الأخيرة. من بين النظريات الأدبية الحديثة، لعبت الشكلانية والبنيوية دورًا هامًا في تقديم علم السردية. يقدم الناقد البنيوي الفرنسي جيرار جينيت- بناء على حدود الرواية - ملاحظات حول علم السرد وهي اليوم لا تزال الدراسة الأكثر اكتمالا في هذا المجال؛ ويركز جينيت - في دراساته السردية- على كيفية قراءة النصوص و هو يرسم لنا صورة نرى فيها كيفية دخول القصص في الأخرى. في الحقيقة يزودنا جنيت بصورة شاملة لنرى فيها عناصرًا مركبة غير محددة عن

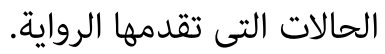


وتعد كوليت الخوري الشاعرة والأديبة والروائية السورية واحدةً من أهم وأشهر الكاتبات في العالم العربي ولها العديد من الكتب والمؤلفات في مجال أدب المرأة والتاريخ ولكن في إيران أعمالها ليست شهيرة بل ولا نجدها. يمكننا تحديد الخصائص الروائية للقصص وذلك عبر دراسة النص الروائي وتحليله. ويساعدنا تحليل الرواية الزمني في التعرف على الترتيب الزمني واللاترتيب في الرواية اللذين يعبران عن نفسية شخصيات الرواية وعن الأجواء التى يعيشونها. كما يمكننا التعرف على أسلوبية المؤلف، عبر توظيف علم السرد وتطبيقه فى النص الروائي، إن كان أسلوبه حديثًا أو قديمًا، الأمر الذي يؤدي إلى التمييز بين القصص التقليدية والحديثة وتحليلها؛ ثم يساعد المتلقي في فهم نفسيات الشخصيات للقصة.

بسبب قضايا مثل التاريخ وقضية المرأة، مل تتمكن كوليت الخوري من متابعة المسار الطبيعي والخط الروائي للأحداث، لقد اجتاح التّوتر والاضطراب تاريخ العالم الشرقي و شهدت التهات الشعوب الشرقيّة أحداثًا مريرة باقية في الذاكرة، وهذا هو الأمر الذي دفع هذه الكاتبة إلى لى لئ استخدام تقنية المفارقة الزمنية، إذن الأحداث في روايات كوليت الخوري لا تأتي عن ترتيب زمني متتابع بل تتّسم باللاترتيب فهي تحاول مشاركة الشخصيات في سرد الرواية لكي تجعل المتلقي مطلعًا على الرواية عبر هذه المشاركة المباشرة في سرد مشاعر الشخصيات و أحاسيسها. منهج البحث: يقوم هذا البحث باستخدام نظرية جيرار جينت على أساس المنهج الاستقرائي والتحليلي والتوصيفي لتحليل زمن الرواية في القصص القصيرة الأربع لكوليت الخوري.

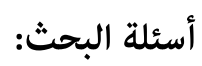

1.كيف يفقد النظام الخطي في الرواية، تسلسله المنطقي ويخضع للمفارقة الزمنية؟ r. كيف تبقى سرعة السرد ثابتة بالمقارنة مع سرعة القصة ؟ r. ما هو الأثر الذي يحدثه تواتر سرد أحداث القصة في السرعة الزمنية الروائية؟ فرضيات البحث: ا. نجد أنه ذهبت الراوية إلى نقطة زمنية أبعد من زمن القصة، في بعض الأحيان، يكون النقل إلى تلك النقطة الزمنية حول الشخصيات الرئيسية في القصة؛ ويعتبر الاسترجاع. من خلال 
ذلك توفر الراوية للقارئ معلومات حول الشخصيات الرئيسية، وفي الواقع، يعلق القارئ أحياناً في تحولات وانعكاسات القصة وهذا هو الحبل الذي ينقذه أو بعبارة أخرى هذه التقنية هي التي تساعد لإصلاح القصة من الفجوة، وهكذا قد تكشف الراوية عن قصة معقدة أو إشكالية.

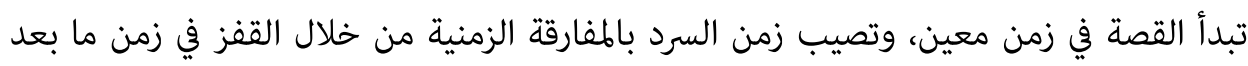
زمن السرد، وهذا يحدث في قصص ليست خالية من العقدة والإثكالية. وتنظر بوضوح تقنية الاستباق.

r. تقوم الراوية أحيانًا إلى سرد الحوارات مباشرةً كشخصية داخل القصة أو كراوية، لذلك لا يمكن أن تتداخل في الحوارات أو تقوم بوصفها وتعبر عن ما حدث مباشرة بنفس الكلمات. بهذه الطريقة، تبقى سرعة السرد ثابتة مقارنة بسرعة القصة من خلال هذه التقنية؛ أي تتساوي سرعة زمن السرد وسرعة القصة. r. الراوية شخصية رئيسة تجرب قصة الأحداث، لذلك، بما أنها تروي الأحداث عند حدوثها، فإنها ليس لديها فرصة لتكرار الأحداث أو تقليلها، لذلك تروي مرة واحدة كل ما حدث مرة واحدة لها. تبدأ الراوية بعض القصص بأكملها بالكلمة "كل" بدلاً من العديد من الأحداث التي مرهاي يختبرها كل يوم، لذلك من خلال سرد مرة واحدة ما حدث عدة مرات، أنها تجعل سرعة السرد أكثر من سرعة القصة. وفي بعض الأحيان الراوية تبطئ زمن السرد من خلال سرد الحدث بشكل متكرر. الراوية كشخصية رئيسة تروي الأحداث التي واجهها مع الشخصية الفرعية في كل مرة.

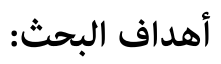
يهدف هذا البحث إلى كشف كيفية توظيف التقنيات الروائية في قصص القصيرة للكاتبة كوليت الخوري. أيضًا يهدف إلى كشف الحالات النفسية لشخصيات الرواية ومكانتهم وتحليل ميزاتها. خلفية البحث:

شهد هذا الحقل دراسات عديدة منها كتاب "خطاب الحكاية" لجيرار جينت وأيضا "بنية الشكل الروائي" لحسن بحراوي و"بنية النص السردي" لحميد لحمداني؛ فهولاء درسوا الزمن 
الروائي خلال دراسة بنية النص. هنا من الأفضل أن نشير الى الدراسات الحديثه التي اهتمت

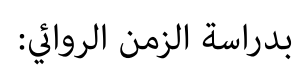

ا. رسالة (تقنيات الزمن الروائي في رواية (حارس التبغ)، لعلي بدر)): تهتم هذه الرسالة

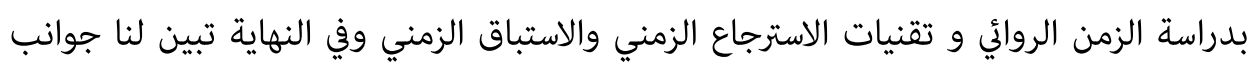
الإبداع والتحول عند الروائي؛ خاصة الانحراف الزمني في الرواية.

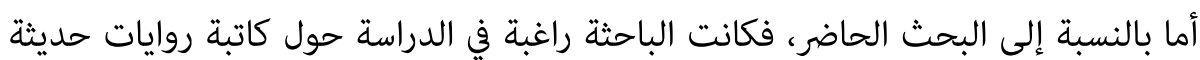
وشهيرة في العالم العربي الحديث، كما كانت راغبة في الدراسة حول كوليت الخوري التي برزت في ساحة كتابة النسوية العربية الحديثة، و فيما درست الباحثة حتى الآن مل تجد دراسة حول الزمن الروائي تهتم بأعمال كوليت الخوري على أساس نظرية جيرار جينيت وهي "النظام"،

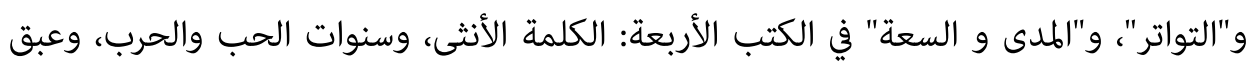
المواعيد، وستلمس أصابعي الشمس. و و التوان.

\section{مباحث في النظرية:}

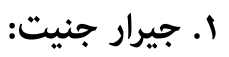

ولد جيرار جينت في باريس بفرانسا و"(عام جعسا، أصبح أستاذًا مساعدًا ثم مديرًا للدراسات في كلية العلوم الاجتماعية للتعليم العالي، الناقد البنيوي الفرنسي، يشير إلى السرد، مع الأخذ في الاعتبار حدود السرد، الذي لا يزال البحث الأكثر شمولاً في هذا المجال، بطريقة أطلق عليه ريتشارد مكزي باعتباره المستكشف الأكثر حداثة في عصرنا في علاقات النقدي والبويطيقي.)، (آلن، 1ـ0با: ص عا). قام جينيت بتحليل وقت السرد للنص بناءً على الزمن النحوي وميز بين السرد و سرد القصة.

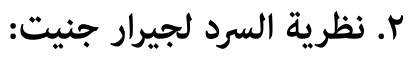

الجدير بالذكر هو أن رالشكلانية الروسية قسمت الروايات إلى مستويين: سيوزه

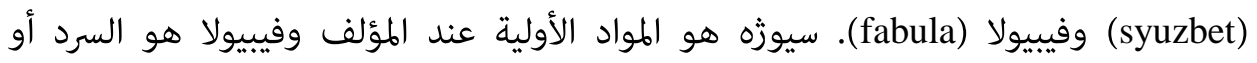
المؤامرة. كما اعتبر بنيويون هذه الأسطح القصصية وزعموا أن القصة تنطوي على أحداث أو أعمال يحاول الراوي إقناع القارئ بقبولها. الخطاب، من ناحية أخرى، ينطوي على كيفية إخبار 


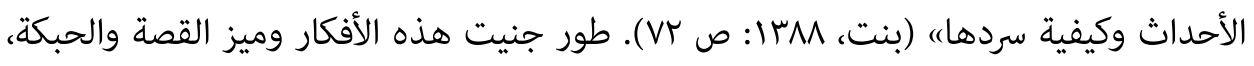
وكان يعتقد أن الأحداث قد جاءت بالترتيب التقويمي في القصة، كما يعتقد أن الحبكة هي التسلسل الذي تحدث فيه الأحداث والسرد. وبهذه الطريقة، استطاع تحليل العلاقة المحتملة بين ترتيب الأحداث في القصة وترتيب سرد القصة. اعتبر جنيت الزمن ووجهة النظر والنغمة،

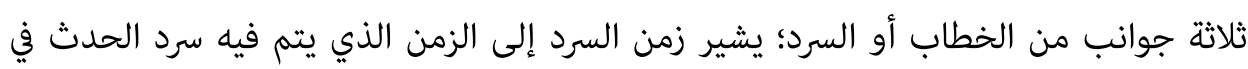
النص. كما أن وجهة النظر هو عمل سرد في الرد على من يطرح له سؤال ويتم تحديد تأثير النغمة من خلال الإجابة عن ذلك السؤال.

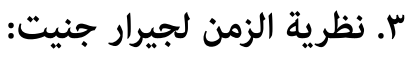
على الرغم من تشابه التعريف السردي من منظور جنيت مع السرديين الآخرين، فإن ما

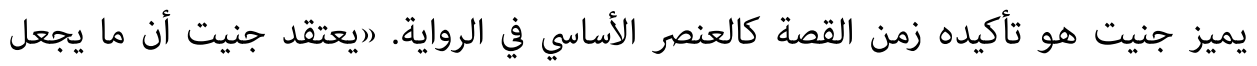
النص السردي جذاباً هو التسلسل الزمني والسببي للأحداث. يرى جيرار جنيت القصة كسلسلة من الأحداث التي ينقلها الراوي للقارئ ويصف السرد بأنه سرد يتم تقديمه بلغة الكلام والكتابة أو له حبكة خاصة. كما أنه يعطل المسار الخطي للوقت ويغير تسلسل الأحداث، وهذا هو النص الفعلي نفسه. بالنسبة إلى جنيت، فإن مقدار الوقت الذي يقرأ فيه النص السردي ووقت التها أحداث القصة هما الوقتان اللذان يشيران إلى الدال والمدلول أي النص الروائي. يعتبر جنيت وقت النص كثيء يتجاوز وقت السرد ويثير مناقشة أشمل للتناقضات بين وقت القصة والسرد في ثلاث طرق: النظام، المدى والسعة والتواتر السردي.) (جنيت: صص حسرواسا). قسم جنيت الزمن إلى زمن السرد وزمن القصة، زمن السرد هو الوصول إلى القارئ وكيفية رواية القصة، وزمن القصة هو الزمن الذي تحدث فيه الأحداث. تتم كتابة زمن السرد من قبل المؤلف فهو ثابت وغير قابل للتغيير، ولكن القارئ هو الذي يغير زمن السرد عند قراءة النص، يتم سرد

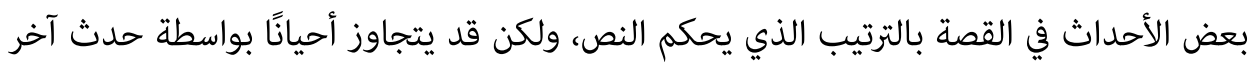
عن طريق فحص ترتيب الأحداث في سياق القصة. 


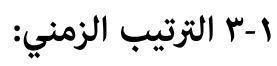

الترتيب أو التسلسل هو الأسلوب الذي يروي به الراوي الزمن السردي في مسار منظم دون الهفارقة الزمنية. (الترتيب هو العلاقة بين تسلسل أحداث القصة والذي يتم ذكرها بواسطته في السياق السردي، في الترتيب الزمني، يتم محاولة تحديد ما إذا كان يتم سرد الأحداث على أساس

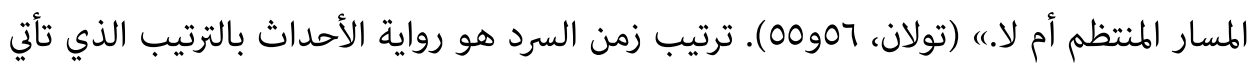
به وفي الواقع، إذا تم تقديم الحدث من قبل الرواي من الصفر إلى الهائة، لقد ظهر مسار خطي في زمن السرد منذ حدوثه، وبالتالي فإن زمن السرد هو عندما يروي الراوي القصة وزمن القصة هو الزمن الذي تحدث فيه الأحداث. لذا فإن زمن القصة ثابت لا يستطيع الراوي التدخل فيه، ولكن يمكن تغيير زمن السرد بإرادة من الراوي وهنا يتم استخدام التقنيات، فإن سرد الأحداث يؤدي إلى ترتيب زمن السرد بالترتيب الذي تحدث. ولكن إذا مل يتم سرد الأحداث حسب ترتيب

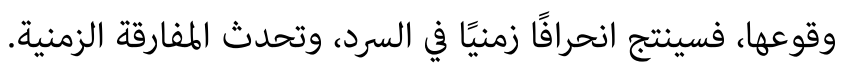

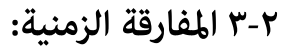

يمكن التعرف على تقنية المفارقة الزمنية بأنه (تعني دراسة الترتيب الزمني لحكاية ما مقارنة نظام ترتيب الأحداث أو المقاطع الزمنية في الخطاب السردي بنظام تتابع هذه الأحداث أو المقاطع الزمنية نفسها في القصة، وذلك لأن نظام القصة هذا تشير إليه الحكاية صراحة أو

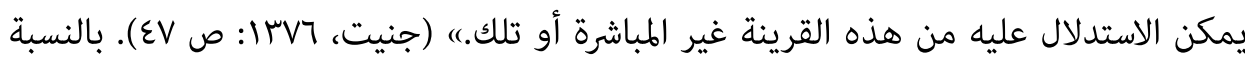
إلى جنيت، يؤدي اللاترتيب في زمن السرد بالنسبة لزمن الأحداث في القصة إلى حدوث تقنية زمن السرد. هذه التقنية تسبب في ترتيب زمن السرد المفارقة الزمنية؛ والمفارقة الزمنية في زمن السرد هي سرد بعض الأحداث قبل أو بعد حدوثها في القصة، بحيث يحدث القفز على مدة زمنية دون إعطاء تفاصيلها أو مع التفاصيل. فيقاطع الراوي الترتيب الذي تحدث به القصة. في المفارقة الزمنية، يتعامل المحلل مع وقوع الأحداث وترتيب سردها في النص. وهذه التقنية بالإضافة إلى تشويش الترتيب الخطي للزمن السردي يغير أيضاً سرعة زمن السرد مقارنة بسرعة لهرة القصة، ويسرع ويبطئ سرعة السرد. على هذا النحو، يعود الاسترجاع إلى وظيفة تقنية المفارقة الزمنية الأولى في زمن السرد، وقسم آخر للمفارقة الزمنية هو الاستباق. 


\section{س-ب المدى والسعة:}

التقنية التالية لزمن القصة في السياق السردي هي المدى والسعة. "يمكن المفارقة الزمنية أن تذهب، في الماضي أو في المستقبل، بعيدا كثيرا أو قليلا عن اللحظة (الحاضرة)، (أي عن لحظة القصة التي تتوقف فيها الحكاية لتخلي المكان للمفارقة الزمنية): سنسمى هذه المسافة الزمنية مدى المفارقة الزمنية. ويمكن المفارقة الزمنية نفسها أن تشمل أيضا مدة قصصية طويلة كثيرًا

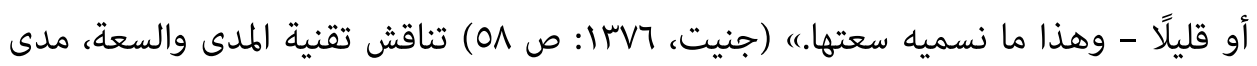
الزمن المطلوب في سرد أحداث القصة. بعبارة أخرى، فإن طول الفترة الزمنية التي يقضيها الراوي في الأحداث، يسمى المدى والسعة. وتُستخدم هذه التقنية في سرعة زمن السرد بطريقة تؤدي أحيانا إلى تسريع زمن السرد بالنسبة إلى زمن القصة وأحيانا أخرى إلى إبطائه. حيث إنه في

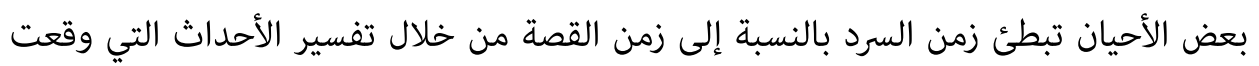
في فترة قصيرة من الزمن. وفي بعض الأحيان تسرع زمن السرد بالنسبة إلى زمن القصة. أما في بعض الأحيان لا يكن التداخل في زمن السرد والتغيير بسبب الحفاظ على الشخصيات في الحوار فيبقى زمن السرد ثابتًا مقارنة مع زمن القصة. واما بالنسبة تقنية التخلص هي عدم سرد بعض بهض الأحداث وحذفها. تقنية إزالة واضحة يحدث عندما الراوي يزيل جزءاً من حياة الشخصية الرئيسية، بحيث يكون القارئ على علم بإزالته. يستخدم الراوي تقنية الحذف الضمني بههارة

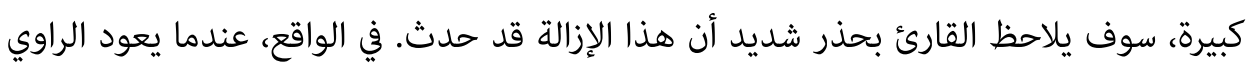

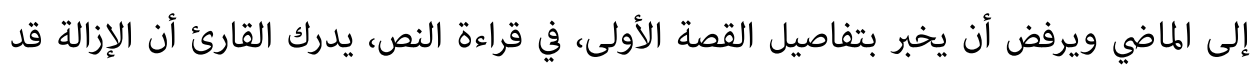
حدث. لذلك تسرع هذه التقنية أيضاً سرعة وقت السرد بنسبة إلى سرعة وقت القصة.

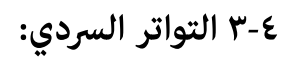

والتقنية الأخيرة لزمن السرد هي التواتر السردي. "(فهو مظهر من المظاهر الأساسية للزمنية

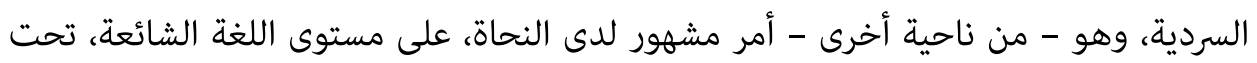

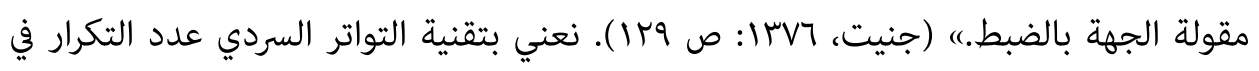
سرد الأحداث. في بعض الأحيان يروي الراوي الحدث الذي جاء فى القصة مرة واحدة فقط. 
ويروي أحيانًا هذا الحدث عدة مرات. يؤثر الراوي على توازن سرعة زمن السرد وزمن القصة من خلال استخدام تقنية التواتر السردي.

ا ا-ع-ب النوع الأول من التواتر السردي هو التواتر السردي الأحادي. (أن يروي مرة واحدة

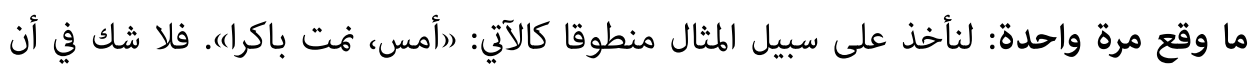
هذا الشكل من الحكاية، الذي يتوافق فيه تفرّد المنطوق السردي مع تفرّد الحدث المسروده)

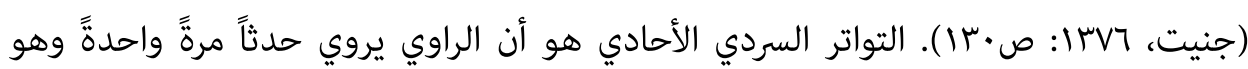
الأسلوب الغالب في كل الروايات.

r-ع-r النوع الثاني من التواتر السردي هو الذي نرى فيه (أن يروى مرّات لا متناهية ما

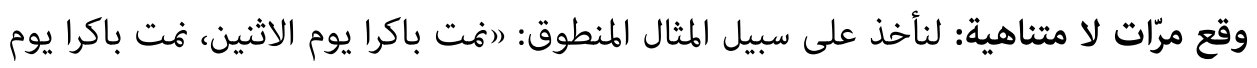
الثلاثاء، فت باكرا يوم الأربعاء، الخ.، فمن وجهة النظر التي تهمنا هنا، أي علاقات التواتر بين

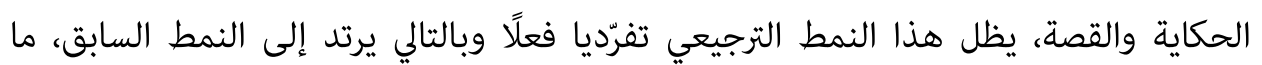
دامت تكرارات الحكاية لا تتعدى فيه - حسب تماثل قد ينعته رومان ياكبسن بأنه إيقوني التوافق مع تكرارات القصة. ومن ثم فالترددي لا يتحدد بعدد الحدوثات من الجانبين، بل يل

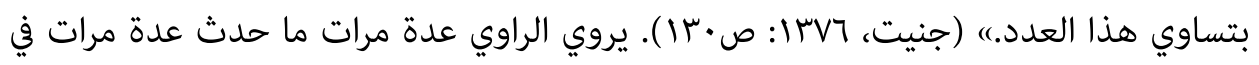
القصة. كما يحافظ على سرعة زمن السرد ثابتة مقارنة مع سرعة زمن القصة.

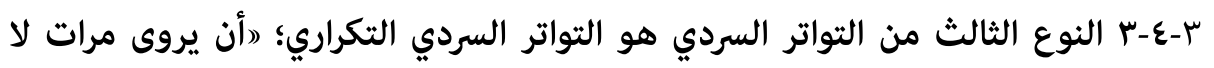

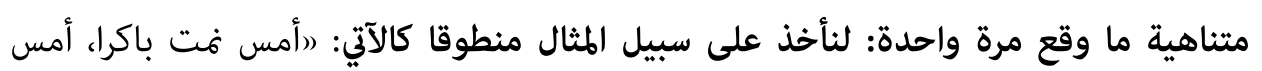
فت باكرا، أمس فت باكرا، إلخ)، يمكن الحدث الواحد مثد أن يروى عدة مرات ليس مع متغيّرات أسلوبية فقط. وقد كانت الرواية الترسّلية في القرن الثامن عشر تعرف هذا النوع من الموجهات،

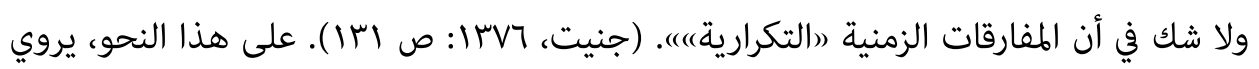
الراوي الأحداث التي حدثت مرةً واحدةً عدة مرات وبالتالي، يبطئ سرعة زمن السرد بالنسبة إلى سرعة زمن القصة من خلال تخصيص المزيد من الزمن لسردها. ع-ع-ب النوع الرابع من التواتر السردي هو التواتر السردي التأليفي. ”وأخيرا، أن يروى مرةً

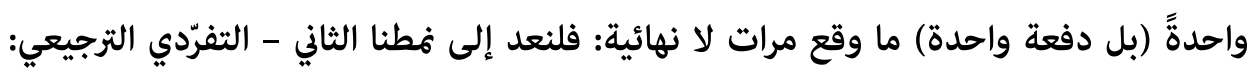
(نفت باكرا يوم الاثنين، الثلاثاء، الخ). هذا النمط من الحكاية، الذي يتولى فيه بث سردي وحيد 
عدّة حدوثات مجتمعة)، للحدث الواحد (أي- مرة أخرى- عدة أحداث منظورا من حيث تماثلها وحده)، سنسميه حكاية ترددية)،. (جنيت، مرةً واحدةً ما حدث مرات عديدة فقط. ويسرع سرعة زمن السرد بالنسبة إلى سرعة زمن القصة من خلال تخصيص القليل من الزمن لرواية القصة.

ع. كوليت الخوري و القصص القصيرة الأربع لها: كوليت الخوري كاتبة ونسوية سورية جعلت المرأة بطلاً لرواياتها وشرحت بذلك ما تواجهها هذا المرأة في المجتمع الأبوي. واستخدمت كوليت الخوري لغة سلسة ونصّاً واضحاً لسرد حياة بطلاتها وتبيين مشاعرهنٌ النسائية. دراسة القصص القصيرة الأربع "الكلمة الأنثى"، "سنوات الحب والحرب"، "عبق المواعيد"، ستلمس أصابعي الشمس" بينت لنا أن الهدف الرئيسي من كتاباتها هو تسليط الضوء على عالم المرأة

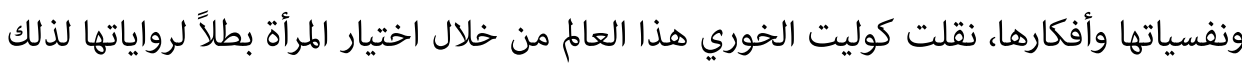
نرى أنّ أساس روايتها هو معتقداتها ومواقفها النسوية ضدّ المجتمع الذكوري ومكانة المرأة المتدنية في المجتمع.

$$
\text { 0. تحليل الزمن الروائي في القصص القصيرة لكوليت الخوري }
$$
ا-ه تسلسل وترتيب الزمن: يأتي تسلسل الزمن في الواقع عندما يتم سرد الروايات على الى الرواي أساس منتظم وفي الواقع يسمى سردًا دون المفارقة الزمنية (الاستباق والاسترجاع). مل تراع كوليت الخوري التسلسل والترتيب الزمني في قصصها القصيرة بسبب تناول الأحداث والتأريخ وقضية المرأة إلخ، وفي كل قصصها نرى اضطراب الزمن. عند فحص قصصها القصيرة، نجد أنها لم تلاحظ الانسجام بين التسلسل الزمني وترتيب القصة. ترتيب زمن السرد هو رواية الأحداث بالترتيب الذي تأتي به وفي الواقع، إذا تم تقديم الحدث من قبل الرواي من الصفر إلى المائة، لقد ظهر مسار خطي في زمن السرد منذ حدوثه، وبالتالي فإن زمن السرد هو عندما يروي الراوي القصة وزمن القصة هو الزمن الذي تحدث فيه الأحداث. لذا فإن زمن القصة ثابت لا يستطيع الراوي التدخل فيه، ولكن يمكن تغيير زمن السرد بإرادة من الراوي وهنا يتم استخدام التقنيات، فإن سرد الأحداث يؤدي إلى ترتيب زمن السرد بالترتيب الذي تحدث. ولكن إذا مل يتم سرد الأحداث حسب ترتيب وقوعها، فسينتج انحرافًا زمنيًا في السرد، وتحدث المفارقة برديب الزمنية. 
ا - ا-0 المفارقة الزمنية؛ العودة إلى الماضي البعيد؛ الاستزجاع:

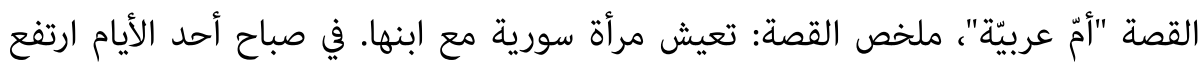
صوت انفجار ثم أعقبه انفجار آخر. وكان الصبي البالغ من العمر عشرين عامًا، خائفًا للغاية

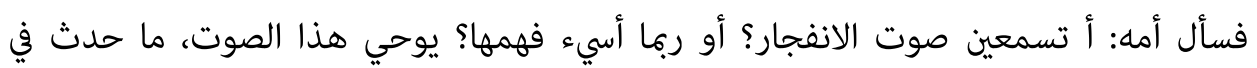
طفولته. طلب المساعدة ممن يقع في المحاصرة والعدو وراءه، أعطوه ملجأ، لكن العدو جاء واجتاح المنزل كله، لكنهم مل يتمكنوا من العثور عليهما، كانا يصرخان من أجل الخوف، وه تكن المرأة تعرف أي جانب أن تأخذ، وكانت تدعم الشاب ابنها. "اتنظر الأم إلى ابنها الشاب وتبتسم في حزن. يغمغم وهو يقترب من النافذة: -هل سمعت؟ صوت انفجار. /تهزّ رأسها غير مقتنعة. /-ليته كان انفجارا. /يضحك في سذاجة بينما تنصت هي في اهتمام. /ليته كان انفجاراً. /فهي تحبّ صوت الانفجار هذه الايام. و...) (كوليت، •^برا:

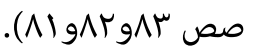
تتمّ الاستمرارية بالأثر الرّجعي في هذا القسم عبر مرور الذكريات المشابهة بالواقع الحالي

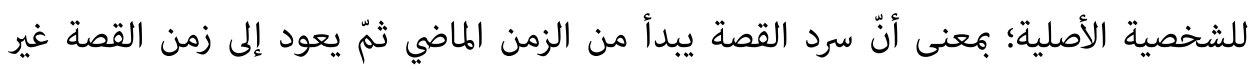
الأصلية (يعني قسما من حياة الشخصية الأصلية)، وهكذا يستبدل الأديب المفارقةَ الزمنية

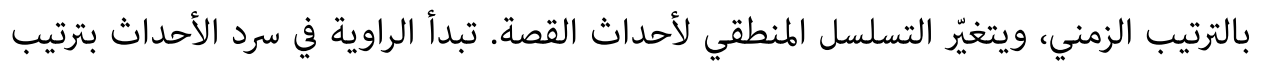
وتسلسل بناءً على زمن القصة (الماضي): (اتنظر الأم إلى ابنها الشاب وتبتسم في حزن. يغمغئم وهو يقترب من النافذة: -هل سمعت؟ صوت انفجار.)، لكن تواصل استخدام تقنية الاسترجاع: ״كان طفلا حين سمع أول انفجار منذ عشرين سنة و...)، يتعلق هذا الاسترجاع بالماضي قبل مهول الحدث الأول للقصة ويرتبط بالشخصية الرئيسة للقصة؛ إنه يعتبر الاسترجاع داخل القصة. وتستخدم الراوية هذه التقنية مرة أخرى؛ للاسترجاع إلى الماضي البعيد للقصة: (بدموعها وبعرق

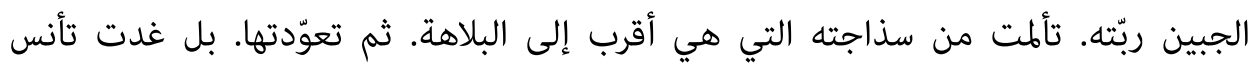

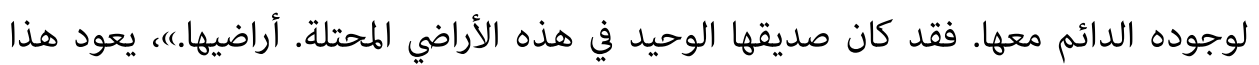
الاسترجاع إلى الماضي قبل وقوع القصة الأولى ولا يشمل الشخصيات الرئيسية؛ فإنه يعتبر نوع الاسترجاع داخل القصة. ثم تعود إلى زمن القصة الرئيس: (الانفجارات تتوالى). 
r-1-0 المفارقة الزمنية؛ من خلال القفز من زمن السرد (الحاضر) إلى زمن القصة؛ الاستباق: القصة "كأس"، ملخص القصة: الشخصية الرئيسة للقصة تحمل فنجانا مليئا بالمياه تحت مت مدئ الشمس، وتشبه الكاتبة حواسها بهذا الماء. الكأس مليئة بالماء، الماء يهتز فيها، يتم تسخينه بواسطة الشمس وتنعكس الشخصية في الماء، كم هي جميلة عندما أنظر إلى هذا الماء كما لو أن

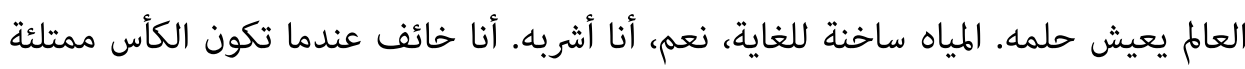
بالماء، إنها مثلي غرقت، لقد عشت في هذا الماء سنوات عديدة، لقد تخلصت من المشاكل، مثل الماء الذي يُشرب، لكن مع نقص المياه، أشعر أن حياة العبث لا معنى لها، أنا لا أحب الكأس مهاء

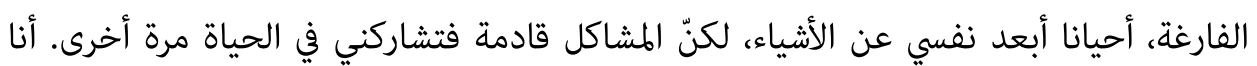
لست قلقاً من أن تكون الكأس فارغًة لأنها تمتلؤ مرة أخرى وسوف أرى العالم فيها. "(مملوءة تتوهج بين يديّ. /نظراتي تفوص في العالم الذهبيّ. تعمرّ فيه دنيا من الأحلام. وتعانق في الضياء الوجه الغالي. /مملوءة تشعشع بين يدي. /وتتسرب أشعتها المحرقة إلى كياني. /فأخاف النار وأرفع الطرف إلى عينيه. /أهرب من شمس إلى شمس. /مملوءة. ولا أحبها

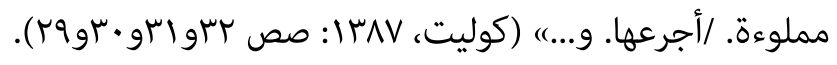
ليس النظام الزمني للقصة نظما خطيا، فالراوي دائا يعكف على تداعيات الزمن الحالي، وفي هذا القسم من القصة يتمّ السفر الزمني إلى المستقبل عن طريق رواية تداعيات أحداث القصة في المستقبل القريب وهو نوع من المستقبلية السردية للقصة. يبدأ سرد القصة بترتيب خطي يعتمد على الأحداث الحالية: (مملوءة تتوهج بين يديّ. و...)، على هذا النحو، يستمر سرد الأحداث على أساس الزمن السردي. حتى تحدث المفارقة الزمنية بين الترتيب الخطي لزمن السرد وزمن القصة: "او يتمتم الصوت المتكبر: -غدا... كلما شربت كأساً في البلاد البعيدة

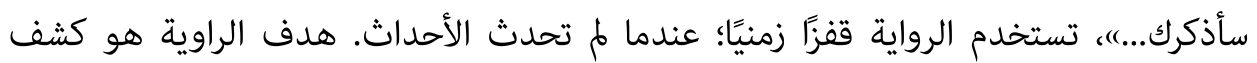
المشكلة في ذهن القارئ بواسطة استخدام هذه التقنية وخصصت ما يصل إلى نصف الرواية لميزات الكأس وتزيل الرواية من التوحيد بواسطة تقنية المفارقة الزمنية. ويشتغل ذهن القارئ بتخمين ما سيحدث في القصة. ثم تعود إلى زمن السرد (الحاضر) مرة أخرى: (امملوءة كأسي بوهم الغد.). تنتهي من السرد بناء على وقت القصة: (رواحمل طرفي السكران إلى عينيه: -لا 
تذكرني... إذا شربت غدا... فغدا... غدا سأشرب لا نساك...)، وهكذا تستخدم المفارقة الزمنية مرتين، والتي تعتبر من نوع الاستباق الذي يهتم بالشخصية الرئيسة فيعتبر استباقًا داخل القصة.

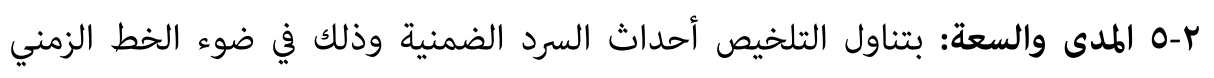
وعندما تسرد الأحداث ترتبط علاقة التلخيص أو الاستبطاء بحيث يرتبط الاستبطاء مع السرد

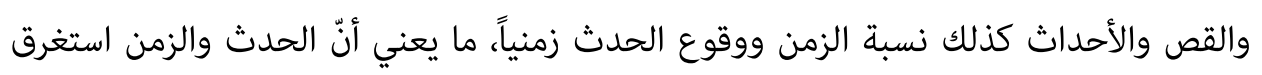
سنة أو أسبوعين أو مئة سنة أو بطئ أو سريع وإلى غيرها من هكذا تيسير زمني بحيث تعالج في التلخيص مدى حجم الحدث وقصره في السرد والقص بحيث تختلف فواصل القص والأحداث وتنتقل من قص إلى قص آخر وتسرد هذه العلاقة بشكل الحوار أو الحذف أو الوصف ولهذا يقوم تساوي زمن القص وفقاً للسرد ما يدل أنّ الوصف عبارة عن تحديد المدة زمنية للقص. المدى هو النسبة بين زمن القصة وزمن السرد. والزمن السردي هو متوسط الزمن الذي تستغرقه

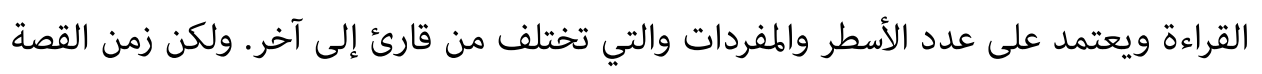
هو الزمن الذي تحدث فيه القصة. بالطبع، يختلف الزمن بين سرد النصوص من نص إلى نص.

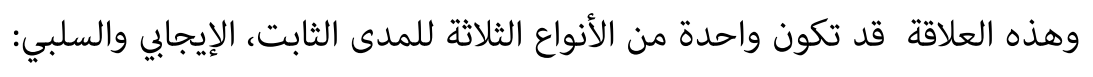
ا ا-r-O المدى الثابت (الحوار)؛ مساواة سرعة زمن السرد بالنسبة لسرعة زمن القصة: القصة "التهمة"، ملخص القصة: يستوجب الضباط فتاة؛ شخصية القصة الرئيسة، ويزعمون

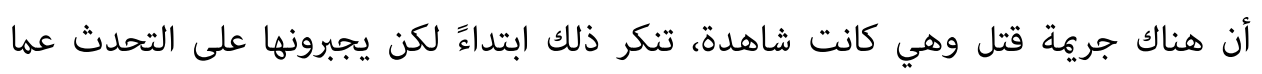

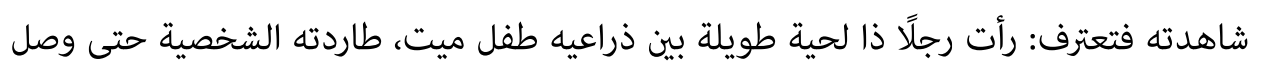

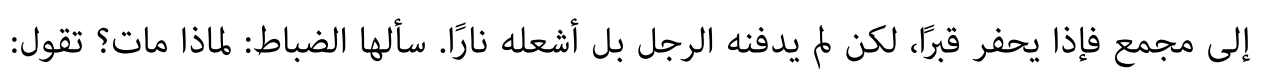
مات الصبي بواسطة ركلات الرجل. ويطلب الضباط منها تحديد ما رأته وشرح آثار الحريق لكنها تقول أنني ما أر أي شيء، مل يقبل الضباط ويسألونها كيف يمكن ذلك وتجيب: أنا أغلقت عيني وفتحتهما بعد القتل، سأل ضباط الشرطة: إذن، ما هي عينيك؟، قالت: عيون ليست

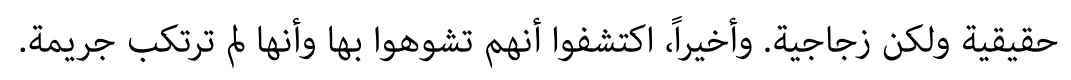

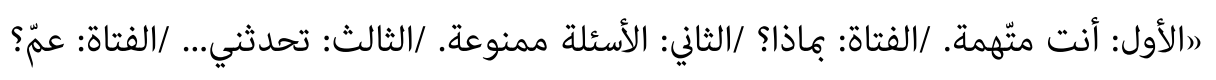
/الثاني: قلنا الأسئلة ممنوعة. /الثالث: تحدّثي. /الفتاة: ... /الأول: هيا تحدّثي. /الفتاة: ... و...)

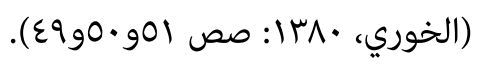


تمثّل قصة "التهمة" قسما من حياة الروائية كوليت الخوري. راوية القصة لا تقيم وزنا للتطويل والتفسير والإطناب فهي تترك الهوامش والشؤون الخارجة عن نطاق القصة كما تحاول أن تجتنب عن الحواشي والاستطرادات والإطناب وذلك عن طريق التطرق إلى الموضوع الرئيسي وسردها في زمن الحال. سردُ القصة في إطار المحادثات وشرح الأمور الجزئية -المرئية والمسموعة-

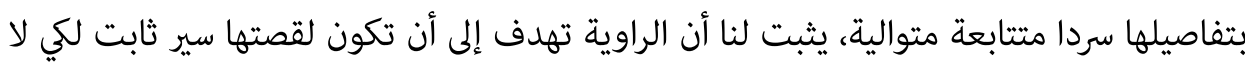
تنسى سرد التفاصيل ولكي لا تكون القصة مُمِلَّة بالنسبة للقارئ. حافظت الراوية على زمن السرد ثابتةً بالنسبة لزمن القصة مع الحوار بين الشخصيات الرئيسية والفرعية. لا يوجد سوى الحوار في سرد الروايات، يوفر السرد للقارئ قصة متشكلة عن الحوار دون إضافة إلى أركان القصة، فإنها تسرع الزمن السردي بالنسبة لسرعة زمن القصة، لذلك يبقى زمني السرد والقصة ثابتين: (أنت مثّهمة. /بماذا؟ /الأسئلة ممنوعة. /تحدثي... /عمّ؟ /قلنا الأسئلة ممنوعة. و...)، تقوم الراوية، وهي واحدة من الشخصيات الموجودة في القصة، بتثبيت سرعة زمن السرد والقصة

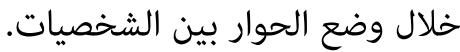
r-r-O المدى السلبي (وقفة وصفية، إطالة)؛ التسارع السلبي لزمن السرد بالنسبة لزمن القصة:

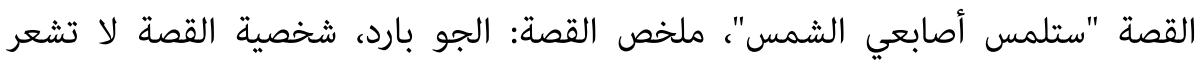
بالرضا، يبدو الأمر كما لو أن كرات الثلج مزعجة، إنها غير راضية عنها الآن، إنها تفكر في حلمها

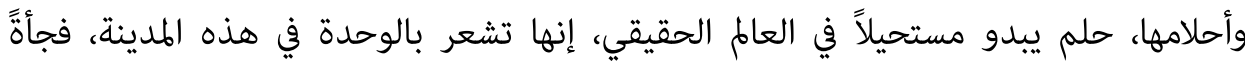

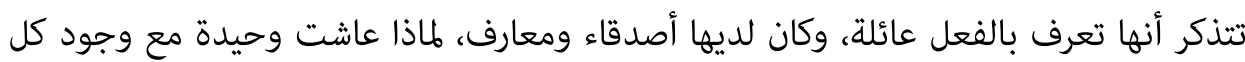
هذه الأشخاص؟، الجو بارد والثلج قد تحول إلى اللون الأبيض، إنها تنظر إلى الخارج وتبدأ بالسير نحو أصدقائها القدامى، تتحدث مع نفسه، نعم، إنهم سعداء برؤيتي الآن، لقد مضى وقت طويل لكنهم لم ينسوني، إنها تتذكر الذكريات مع الأصدقاء وتبتسم، تذهب في طريقها، وفجأة تذهب إلى المنزل الذي كانت تسكنه في طفولتها، لقد تغير ظاهر المنزل قليلًا، تتحدث مع أحد أعضاء المنزل، لكنه يجيبها ببرودة، إنها تريد العودة، لأنه لا أحد يتذكرها بعد الآن، تصر

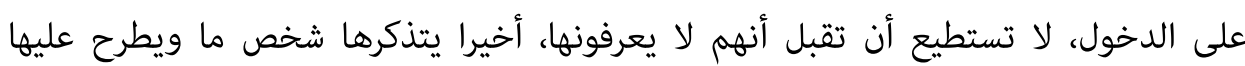
أسئلة، مازالت تأمل في الوصول إلى هدفها وستلمس أصابعها الشمس. 
״أظلم وجودي، /وهطل امللل على بيتي وغلّل قلبي... /وتساقطت الثلوج السود على طموحي وآمالي... /فسرى الصقيع في عروقي، وشعرت بخوف جارف يدفعني إلى الطريق. و...)

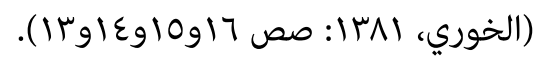
نرى أنّ الأوصاف الجامدة والتباطؤ الوصفي متواجدان في قصة "ستلمس أصابعي الشمس" ماتوال

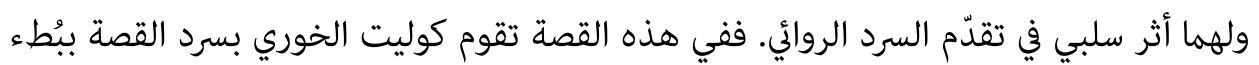
وذلك بسبب تناولها وصف الوقائع الجزئية بكل تفاصيلها. تروي الراوية، ودورها دور الشخصية الرئيسة، القصة أولاً عن طريق معالجة تفاصيل القصة وتعرض عقدة القصة للقارئ من البداية. وتصف أحداث القصة: (أظلم وجودي، /وهطل الملل على بيتي وغلّل قلبي... و...)، الزمن يمضي ببطء في السرد، تتجاوز سرعة زمن القصة، زمن السرد وبالتالي فإن الموضوع الرئيسي للقصة غير واضح للقارئ. تفرض الراوية على القارئ متابعة السرد مع التفكير من خلال العقدة وتخمين الحدث التالي. ثم تقترب من أصل القصة: ("ولكنني وقفت في الطريق، ونظرت إلى الى الأمام...)، تقرب الراوية نسبة سرعة زمن السرد إلى سرعة زمن القصة. ولكن بعد ذلك من خلال القيام بالوصف، فإنها تبطئ سرعة زمن السرد مرة أخرى: (الطريق طويلة، شاقة، مظلمة، وأنا وحدي! و...)، الراوية تنصرف من معالجة القضية الرئيسة وتحاول توسيع القصة بقضايا بسيطة، مع هذه التقنية، تقلل من سرعة زمن السرد وتزيد من سرعة وقت القصة. تستمر هذه السرعة البطيئة حتى نهاية القصة.

ץ-ץ-0 المدى الإيجابي (المجمل)؛ التسارع الإيجابي لسرعة السرد بالنسبة لسرعة القصة: القصة "الجبل"، ملخص القصة: الشخصية الرئيسة للقصة تلتقي أحد معارفها في الفندق، إنها ليست في حالة مزاجية جيدة، وأخيراً نفهم أنها شاعرة ويجب عليه المشاركة في بضع زيارات شعرية مع الأصدقاء، لكنها ظلت صامتة لبضعة أيام. وكانت صديقتها غاضبة واحتجت لها. لكنها لم ترفض احتجاجها، موضحةً سبب صمتها عن طريق تشبيه نفسها بالجبل. هناك نافورة المياه في الجبل وذات مرة رفعت النافورة صوتها بحرية وتكلمت: نعم، صديقتي قصتي مثل هذا

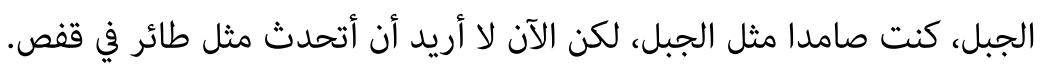


״لا أيها السيد... لا! /دعني وجراحاتي، دعني أبكي وأصوغ من دمعي سبحات وصلوات. /دعني أشق طريقي بنفسي وأبحث في ضياعي عم وجودي. لا! /لا تلملم مبعثرات نفسي. دعني مشردة. ولا تحاول إيناس وحشتي. دعني وحيدة. فقوتي في وحدتي... أيها السيد! و...) (الخوري،

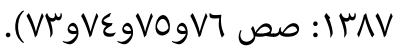
تأتي الأحداث في قصة "الجبل" مستخلصا وعند توظيف أسلوب الحذف، يـشي الزمن تلقائيا لكن الكلام عندئذ تتوقف نهائيا. سياق الحذف في الحقيقة يسبب في تسريع مرور زمن القصة والغريب أن الحذف لا يخضع للسرد، فهو في والواقع يُعتبر نوعا من عناصر التي تقوم بتسريع الزمن السردي في القصة. والحذف الذي يؤدّي إلى الإيجاز يُعدّ من عناصر الجمال في بناء قصة "الجبل". ففي هذه الرواية يتمّ حذف كثير من الأزمنة عبر التجاهل الزمني لكي تتجلى الأحداث وأهداف التي تُعنى بها الكاتبة. على سبيل المثال لا تتناول كوليت الخوري تفاصيل الأحداث وتواصل سرد القصة بححادثات تجري بين شخوص الرواية. تبدأ الراوية التي تلعب نفسها دور بطل القصة، وتخاطب إحدى شخصيات القصة الفرعية، إنها تتحدث عن المصاعب والصعوبات التي تعاني منها. ومع سرد الأحداث في المسار الطبيعي للقصة، تتماشى سرعة السرد مع سرعة

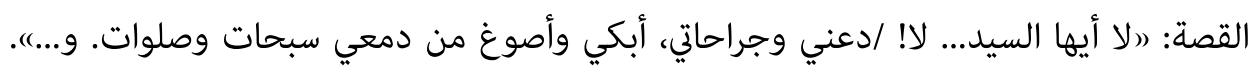
ولكن بعد ذلك، تتواجد التقنية أكثر فأكثر وتصبح سرعة السرد أكثر من سرعة القصة: (أيام قليلة جمعتنا في هذا الفندق الكبير.)، أمضت الراوية عدة أيام في الفندق، دون إعطاء تفاصيل عما تفعل في الفندق، بل تقدم للقارئ وصفاً مختصرًا لهذه الأيام. تتجاوز سرعة السرد سرعة القصة. ثم ترجع سرعة السرد والقصة إلى التوازن مرة أخرى: ("شاعرة مشردة"... /هكذا قالوا لك. فروى غرورك هذا التشرد وأثار قوتك. و...). ولكن بعد ذلك تقوم التلخيص وتسرع سرعة وقت السرد: (وكانت الرجولة فيما مضى تغريني... و...)، وبهذه الطريقة، تلخص لحظة في حياتها، وبالتالي فهي تقلل من زمن السرد وتضيف إلى سرعة القصة. من خلال هذه التقنية، تخرج القارئ من عدم اليقين وتقدم الموضوع الرئيس للقصة دون وصفها قبل انتهاء القصة. فإن الاستمرار في سرد الأحداث في المسار الطبيعي للقصة تحافظ على سرعة وقت السرد والقصة في حالة توازن: (ما زال العتاب يطير إلى من عينيك سهاما. و...). بقدر ما تستمر الروايات، إنها تستخدم أسلوب الملخص: (أحطتني باهتمامك خلال الأيام الفائتة وأدهشتك لا مبالاتي.)، تتكلم القارئة عن صلب 
الموضوع دون وصف الأحداث. وتتابع سرد الرواية في موازنة بين سرعة السرد والقصة إلى نهاية

آخر مقولة في زمن القصة وزمن السرد وهو علاقة يحدث بين الأحداث وبين السرد ويسرده السارد لتكثيف الزمن والحدث. يعتمد ذلك على تكرار الحدث عدة مرات في سياق السرد. في الواقع، العلاقة بين عدد تكرار الأحداث وعدد تكرار ذكرها ويشمل ما يلي:

\section{ا-ץ-0 التواتر السردي المنفرد؛ سرد مرة واحدة ما حدث مرة واحدة:}

القصة "هذا المجتمع"، ملخص القصة: الشخصية الرئيسة للقصة مدعوة للحضور في حفل، سيقام الحفل في الفندق الذي تقيم فيه، يحدث الحدث كل عام وتمنح جائزة لأفضل الفنان في مجال تصميم الملابس. الجو بارد في تلك الليلة، اختارت "خولة" فستانها الأسود الطويل للحفل، كان الحفل في الطابق العلوي، تتسلق الدرج، مل يصدر صوت من القسم الذي أقيم فيه الحفل،

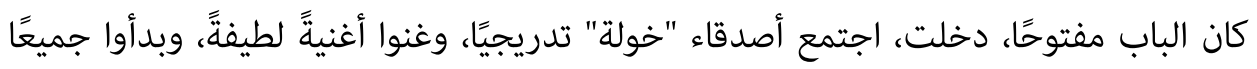
يرقصون مع أصدقائهم، بعد الرقص، حان الوقت للجائزة. في حين أن "خولة"، مع كل النظرات المذهلة على فستانها، مل تعتقد أنها ستحصل على الجائزة الأولى، ولكن على عكس خيس خياله، منحت الجائزة الأولى وبعد ذلك الثانية والثالثة.

"ثوبي عاديّ. حيك على مقاييس جسدي. /لكنّني أخاف البرد، وأخشى أن تلوّث الزوابع والأمطار بياضه الناصع، فأتلمّس معطفي الأسود وأرفع يدي إلى الياقة ألصقها بجيدي وأدخل

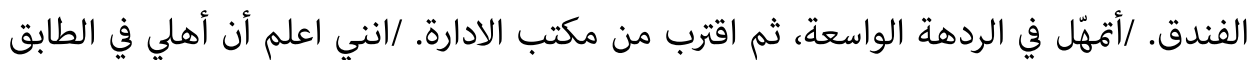
العلوي مع لفيف من اصدقائهم. وقد استطعت أن أرى بعض هؤلاء يتبخترون على الشرفة

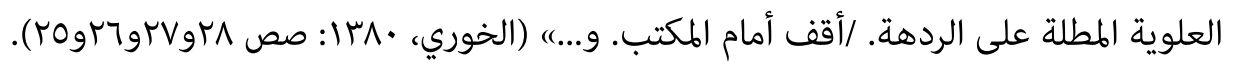
بشكل عام، التكرار في سرد رواية "هذا المجتمع" هو الجزء الأساسي من عقلية الراوية. وفي هذه الرواية، يتم سرد كثير من الأحداث في إطار المدى المفرد. لكننا نستطيع أن نرى أبرز هذه

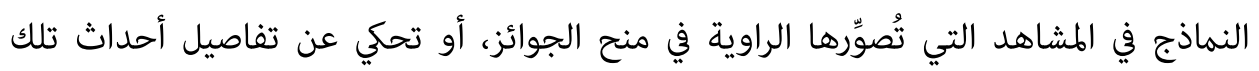
الليلة. في هذه القصة، تروي الراوية، بصفتها الشخصية الرئيسة، الأحداث بهجرد حدوثها: (ثوبي 
عاديّ. حيك على مقاييس جسدي. و...)، تجرب الراوية أحداث القصة وتروي الأحداث وقت حدوثها لذا ليس لديها فرصة لتكرار الأحداث أو تقليلها، لذلك تروي كل حدث مرة واحدة: ״أقف أمام المكتب. /لا مبالاةٌ غريبة، بل شعورٌ يشبه الاطمئنان يمنعني من الصعود إليهم. وربما انا ما كنت أودّ أن أصهد إليهم أصلا، فالاختلاط بهؤلاء ما راق لي يوماً. جئت فقط للأطمئنان. فأنا أحبّ أهلي.)، الراوية مدعوة للحضور في حفل تمنح فيه جائزة للفنان الذي ارتدى الفستان الأجمل، منذ اللحظة الأولى لحضورها حتى زمن إعطاء الجائزة، تروي الأحداث مباشرةً. تستمر أسلوبها في ذكر الأحداث مع السرد المتزامن للأحداث حتى نهاية القصة: (روقبل أن أفكر فيما اذا كنت سأبقى في الردهة أم سأمضى، تتسرّب إلى سمعي من شقّ باب كبير قبالتي ضجّة غريبة. -هذه حفلة تنكرية يقيمها شباب المدينة. و...).

\section{ץ-ץ-ه التواتر السردي؛ سرد مرة واحدة ما حدث أكثر من مرة:}

القصة "قلق"، ملخص القصة: تتحدث شخصية القصة الرئيسة عن شدة حبها لحبيبتها. يمنو هذا الحب أكثر فأكثر؛ أحبك أكثر من أي وقت مضي، حتى التفكير في الأمر صعب بالنسبة لي أن أخرج ذات يوم وأن أكون منفصلاً عنك، ثم كيف تعيد الحياة ليلا وتعيش حياة طبيعية. "ركلّ يوم يحتلّ طيفك في قلبي مكاناً أكبر... /كلّ يوم يتّسع وجودك في حياتي وأشتاق إليك أكثر... /لست أدري كيف غدا سأحتمل غيابك /لماذا سأمحو لن سأشدو وكيف سأسهر /خائفة

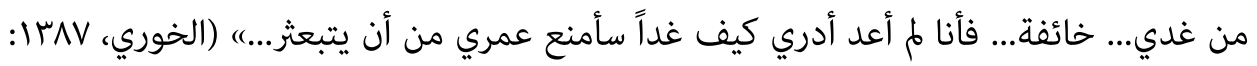

$$
\text { صص (1) (1) (1) (1) (1) }
$$

تحكي الراوية عدد السرد الروائي للأحداث على أساس أهمية تلك الأحداث، فرواية "قلق" هي سرد خيبة كوليت الخوري عن عشيقها فهي تعتقد بأن قصة حبها انتهت نهائيا، وتمتنع عن سرد الأحداث للمرة الثانية. وتقوم بتسريع الزمن السردي عن طريق السرد الشامل عن تلك الأيام، أيام حبها. تروي الشخصية الأولى حدثاً يتكرر كل يوم كما لو كان مرة واحدة: ״كل يوم يحتلّ طيفك في قلبي مكاناً أكبر... /كلّ يوم يتّسع وجودك في حياتي وأشتاق إليك أكثر...)، تبدأ الراوية القصة بأكملها بحرف "كل" بدلاً من العديد من الأحداث التي تجربها كل يوم، لذلك من خلال سرد مرة واحدة ما حدث عدة مرات، أنها جعلت سرعة السرد أكثر من سرعة القصة. 
ب-ץ-ه التواتر السردي التكراي؛ تكرار السرد ما حدث مرة واحدة: القصة "قصتي قصة...!"، ملخص القصة: هذه القصة هي تعريف لعالئن مختلفين، عالم ما قبل الحرب وعالم ما بعد الحرب. أولاً، تجدر الإشارة إلى آثار الحرب، والتي حولت الأمل إلى يأس. أما بالنسبة للزواج، كان على النساء ما قبل الحرب فقط رعاية أزواجهن وعائلاتهن، لا

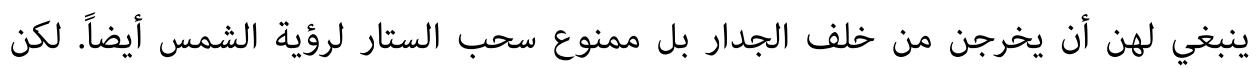

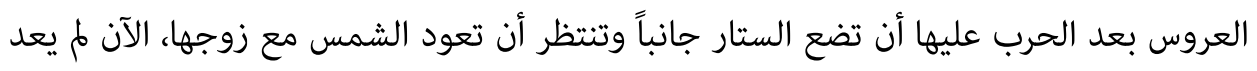
زواج العروس والعريس ذا معنى لأن العديد من العرائس أو العرسان يقتلون ويتركون أزواجهم مفردهم. الآن علينا أن نسلّم الفتاة للغرباء لأن أبناء الأسرة قد قتلوا في الحرب وليسوا أحياء. "اقصتي وهذه الزاوية الحرة.. قصة! /إذا رويتها وشرحت... "جرصة!" /وإذا سكت... خنقتني الغصة! /من الأفضل أن يتكفل قلمي كعادته بحل المشكلة! ولكن... آه يا قلمي... /أليست قصتك هي القصة؟ /من أولها... /بعد حرب تشرين الرائعة، تلك الحرب التي في رأيي، غسلت

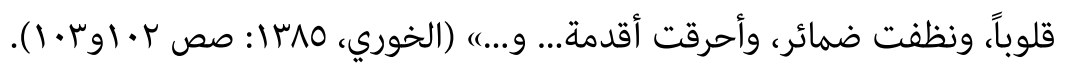
حكاية "قصتي قصة" هي سرد وقائع حرب في سوريا، والراوية تعبّر عن أهمية هذه الواقعة بإعادة سردها عدة مرات وهي حدثت مرة واحدة فقط. فتقوم -عبر هذه التقنية- بتباطؤ الزمن السردي وتُوقّفها عن الحركة. تكرر الراوية عدة مرات الحدث الرئيسي (الحرب) الذي حدث مرث مرة واحدة في القصة: "بعد حرب تشرين الرائعة، تلك الحرب التي في رأيي، غسلت قلوباً، ونظفت

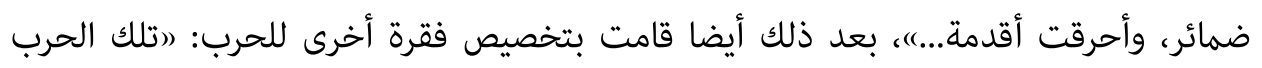
التي محت الفوارق، وأزالت الحواجز، وبرهنت أن الجميع خلايا حية في جسد واحد...)، وأيضاً الفقرة التالية: (بعد تلك الحرب...)، وبعد القيام ببعض الوصف، عادت إلى الحرب: (هذا القلم المغامر، عاشق الحرية والعزوبية، انتفض نشوان، بعد حرب تشرين، وقرر أن يتزوج!ه، تتحير الراوية بقصة الحرب وتتكرر هذا الحدث مرارًا، من خلال هذه التقنية تبطئ سرعة السرد بالنسبة لسرعة القصة حيث يجب على القارئ قراءة قضية الحرب مرات عديدة والتي حدثت مرة واحدة في القصة؛ الأمر الذي يقلل من زمن السرد وعلى عكس ذلك، فإنها تسرع زمن القصة. وتتابع تكرار ما حدث مرة واحدة في القصة: (رتأملها العريس بعد حرب تشرين وقد وقد 
وقفت أمام النافذة المشرعة للشمس، فبدت له هي الأخرى عائدة من المعركة، مرتدية الكاكي، و...")، وبالتالي، فإن الراوية تبطئ زمن السرد من خلال سرد الحدث بشكل متكرر.

ع-ץ-0 سرد الحدث عدة مرات؛ تكرار ما حدث عدة مرات:

القصة "ثرثرة نساء"، ملخص القصة: الشخصية الرئيسة هي امرأة تتحدث عن العادات

الأنثوية. عندما يجتمعن مع البعض، ويتكلمن عن ما حدث لهن، كما يتحدثن عن الرجال ويعبرن عن آرائهن، تتحدث المرأة مع صديقاتها حول صبي يرجع تاريخه إليها منذ شهرين، اسمه "عدنان"، عندما تتوفه بكلمة "عدنان"، تعرفه أحدى صديقاتها لذلك تخشى ألا يعرفن

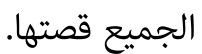
"رنحن صديقتان على الرغم من أننا لا نلتقي إلا نادراً. /ولكن كلما التقينا نسينا الفترة التي فرقت ما بيننا وشعرنا أننا لم نفترق إلا في الأمس. /لهذا السبب نختصر في كل لقاء لنا فترة غيابنا فتلخص كل واحدة منا للثانية بعفوية كل الحوادث التي مرت معها خلال فترة التباعد. /ومع

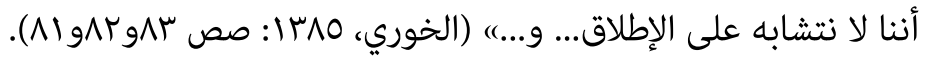
تقوم كوليت الخوري في سرد القصة بإعادة المحادثات التي تجري بين الشخصيات غير الأصلية، فكانت الخوري كعامة الناس تولي اهتماما بعيدا بالهحادثات الودية بين النساء، إذن لهن توقِّف السرد الروائي بإعادة محادثات شخصيات القصة، محاولة تقديم الزمن الروائي وتقديم أحداث القصة في إطار مشترك. الراوية كالشخصية الرئيسة تروي الأحداث التي واجهتها مع الشخصية الفرعية في كل مرة: (... ولكن كلما التقينا نسينا الفترة التي فرقت ما بيننا وشعرنا أننا مل نفترق إلا في الأمس. /لهذا السبب نختصر في كل لقاء لنا فترة غيابنا فتلخص كل واحدة منا للثانية بعفوية كل الحوادث التي مرت معها خلال فترة التباعد.)، تروي الراوية عدة مرات التقاء الشخصيات للقصة وتحدثها مع البعض وتبقى سرعة السرد ثابتة مقارنة مع سرعة القصة وهذا بواسطة تكرار ما حدث عدة مرات. كما نرى هنا أنها تكرر نفس الحدث: "(والتقيت بها في الأمس بعد شهري غياب. كنا خلالهما غارقتين في أعمالنا، لا تسمع واحدتنا صوت الثانية إلا عابراً على الهاتف. و...)، وبالتالي فإن الراوية تطبق هذه التقنية على أجزاء السرد وتبقي سرعة السرد ثابتة مقارنة مع سرعة القصة. 


\section{النتيجة}

تتناول المفارقاتُ الزمنيةُ موضوعَ القصة فقط وقلّما يحدث أن تتطرق إلى الشؤون الخارجة عن نطاق القصة. التطرق إلى سرد الحوادث الخارجة عن القصة يسبب في تشرّد ذهن القارئ فيبتعد عن تسلسل الأحداث وقد يحتاج القارئ إلى زمن كبير للعودة إلى أجواء القصة وذلك عندما يكون سرد الأحداث الخارجية سردا طويلا. ولا تستطرد كوليت الخوري في سرد القصة استطرادا كثيرا لكي تجعل ذهن القارئ يركّز على القصة فهي قامت بتقليل سرد الأحداث الخارجة عن نطاق الموضوع الرئيسي إلى أدنى مستواه. وفي المقابل تناولت المفارقة الزمينية

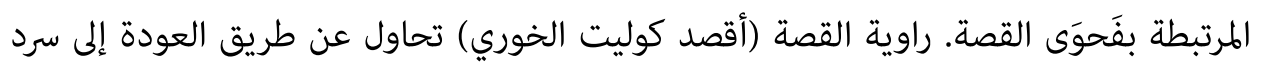
الأحداث الماضية للقصة، إحياء تلك الوقائع في ذهن القارئ وذلك بغية التأكيد على ضرورة

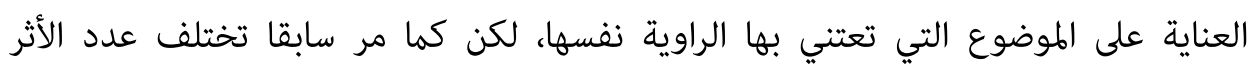
الرجعي في القصة نظرا إلى ظروف الراوية وماهية وقائع القصة، فهو يكثر حينا وينخفض حينا

التوقفات الوصفية والتشريحية والمشاهد المسرحة في القصة، لها دور سلبي في تسريع السرد الروائي وهي التي تؤدّي إلى توقّف النشاط الزمني أو تباطؤه.

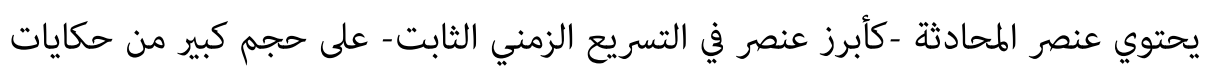

من جانب آخر يتم توظيف أنواع التواتر السردي في هذه القصة، لكن التواتر الأكثر توظيفا هو التواتر المفرد الذي يشمل الأحداث التي تحدث مرة واحدة ويتم سردها مرة واحدة أيضا. وتواتر إعادة الرواية، يتم توظيفه في الأمور التي ترتبط برتابة الحياة، كما يتم توظيف التواتر المتكرر في إعادة سرد كل واقعة بعد سردها الأول.

يتمّ توظيف الإيجاز والحذف والقفزات الزمنية الكبيرة في القصة، وهي من الأساليب التي تساهم في التسريع الزمني الإيجابي؛ يتمّ سردُ بعض الأحداث بإيجاز، والطسار السريع في الأحدث -والذي هو يتابع المحذفات المتوالية والفرغات الزمنية- يقوم بتسريع السرد الروائي. 


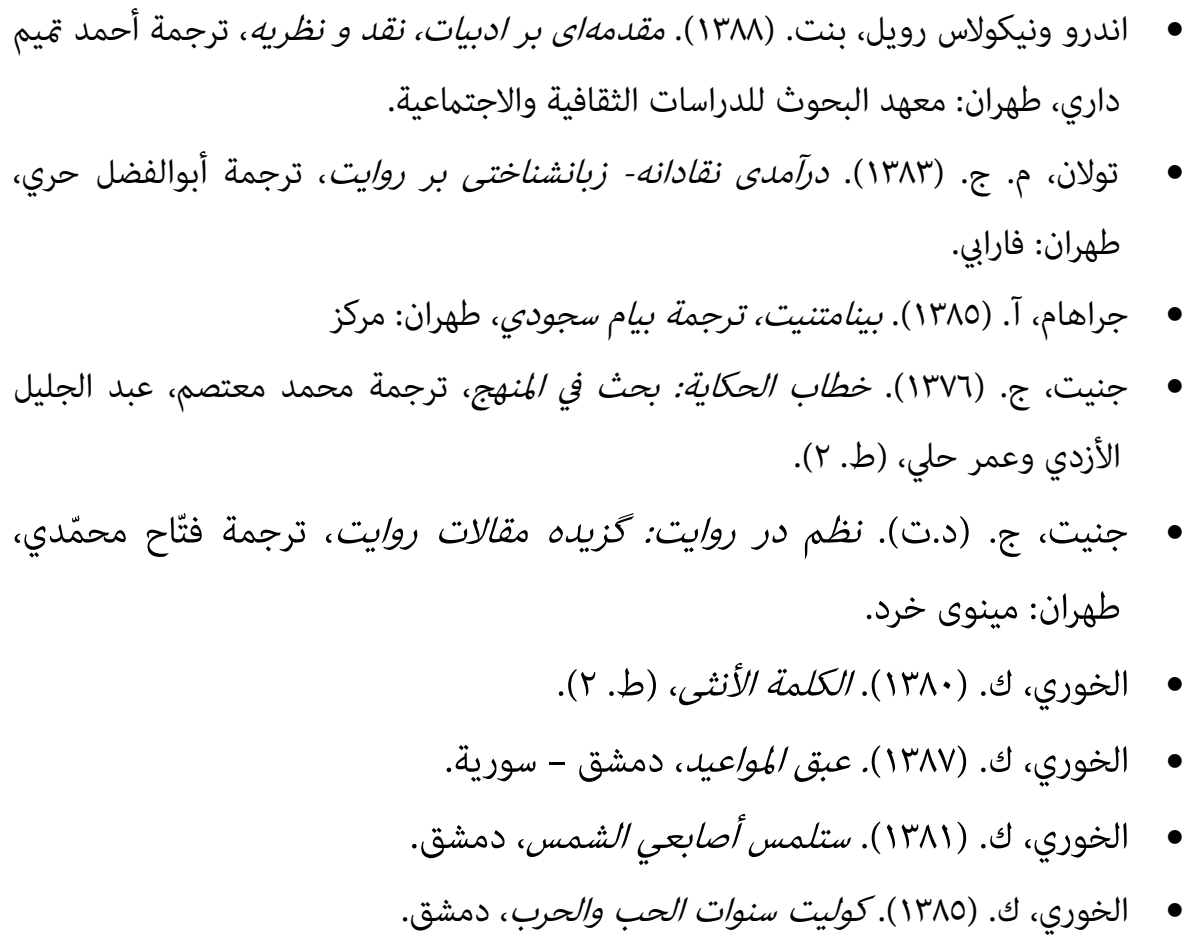

\section{References}

- Andrew and Nicolas Roel, Bent, (2009). "Introduction to Iiterature: criticism and theory". Translated by Ahmed Tamim Dari, Tehran: Research Institute for Cultural and Social Studies.

- Tolan, M. G. (2004). "Critical income-language narrative". Translated by Abolfazle Hori, Tehran: Farabi.

- Graham, A. (2006). "Intertextuality".

- Genet's, G. (1998). Story letter: Curriculum research. (2nd ed), Abdol Jalil Al-Azdi and Omar Helli.

- Genet's, G. (?),Poetry in Narration: Excerpts from Narrative Articles, translated by Fattah Mohammadi, Tehran: Minavi Kherad.

- Khoury, C. (1971). Female word. (2nd ed).

- Khoury, C. (2008). Fragrant appointments. Damascus-Syria.

- Khoury, C. (2002). My fingers will touch the sun. Damascus.

- Khoury, C. (2006). Years of love and war. Damascus. 


\section{مطالعات روايت شُناسى عربى}

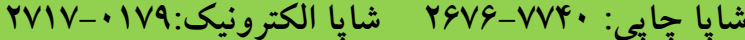

زمان روايى داستانهاى كوتاه كوليت خورى بر اساس نظريه زرار زنت

ramezani@atu.ac.ir

رايانامه:

ربابه رمضانى

استاديار گروه زبان و ادبيات عربى، دانشخاه علامه طباطبايى، تهران، ايران mina.nikjo97@gmail.com رايانامه:

مينا نيكجو

كارشناسى ارشد زبان و ادبيات عربى، دانشخاه علامه طباطبايى، تهران، ايران. (نويسنده مسئول)

جكيده

روايت شناسى مجموعه اى از احكام كلى درباره ى سبك هاى روايى، نظام هاى حاكم بر روايت يا داستان

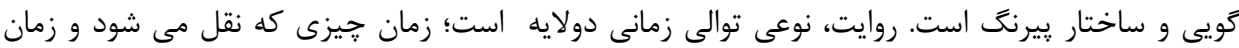

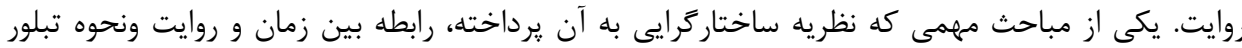

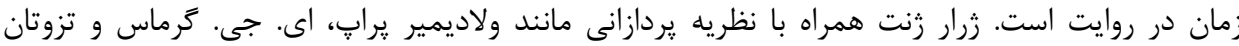

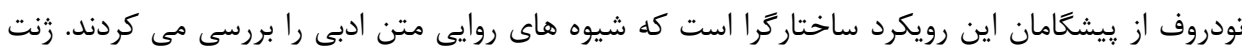

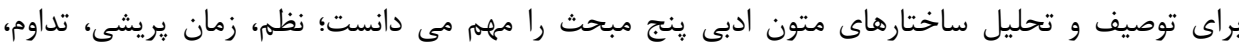

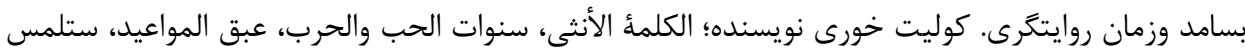

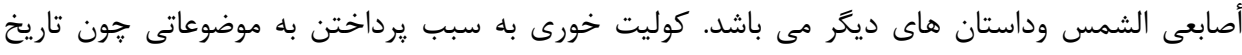

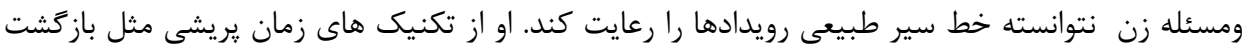

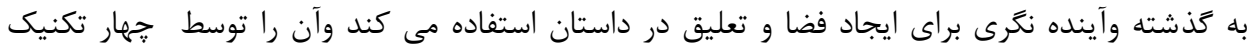

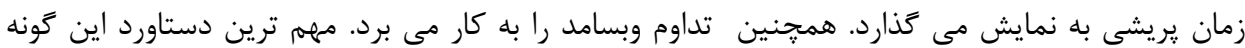

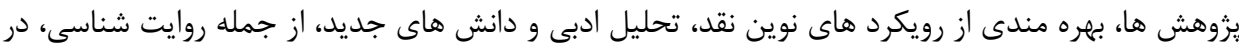

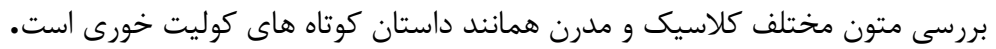
كلمات كليدى: روايت شناسى، زرار زنت، زمان روايى، كوليت خورى، داستان هاى كوتاه.

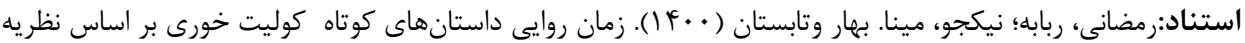

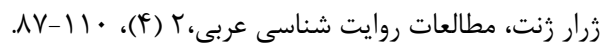

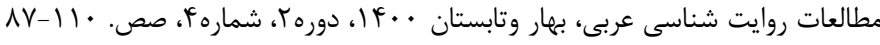

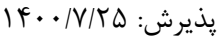

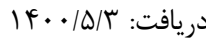

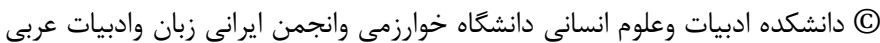

